Gao, S., Liu, J., Zheng, H., \& Wu, F. (2021).Evaluation of Individual Contribution in Blended Collaborative Learning. Journal of Educational Technology Development and Exchange, 14(2), 91-106.

\title{
Evaluation of Individual Contribution in Blended Collaborative Learning
}

\author{
Shurui Gao \\ gsr97@foxmail.com \\ Jiaqi Liu \\ liujiaqi1212@foxmail.com \\ Haolin Zheng \\ 202121010213@mail.bnu.edu.cn \\ Fati Wu* \\ wft@bnu.edu.cn \\ Beijing Normal University
}

\begin{abstract}
With the deepening of classroom teaching reform, blended collaborative learning has become a common collaborative learning method, and its significance and value have been verified by many parties. However, there is still a lack of quantitative analysis and detailed insight into the internal interaction dynamics of the group at the individual level. There are limitations in the evaluation dimensions and methods of individual contribution in collaborative learning in previous studies, therefore, it is difficult to obtain a comprehensive evaluation of individual contribution. In this study, an evaluation model of individual contribution in blended collaborative learning was constructed, which mainly involved four dimensions of knowledge contribution, emotional contribution, organizational contribution and achievement contribution. Moreover, discussion recordings and text data in collaboration were collected in a non-invasive way to validate the model. Based on the evaluation model, the characteristics and rules behind the data were deeply explored. The collaborative process of the blended collaborative learning was analyzed and mined. The characteristics of learners' contribution were summarized to support the development of blended collaborative learning.
\end{abstract}

Keywords: blended collaborative learning, individual contribution, learning analysis 
Collaborative learning is an activity in which two or more learners study together and share ideas in order to better understand a learning topic, solve key problems, or form a project proposal. With the deepening of classroom teaching reform, blended collaborative learning has been widely applied in many courses (Gao, 2021). Although the advantages and significance of collaborative learning have been proved in many empirical studies, there is still a lack of quantitative analysis and detailed insight into the internal interaction dynamics of the group at the individual level.

\section{Statement of Problems}

\subsection{Evaluation of Collaborative Learning Tends to Ignore the Difference of Individual Contribution}

Accurate assessment of individual contribution is crucial in a collaborative learning process. In the previous collaborative learning evaluations, academic performance was mostly scored in terms of a group, and the performance of each group was usually measured according to the course assignments or works (Bacon, Stewart, \& Silver, 1999), while the contribution of individual learners in collaborative learning and their influence on team members and collaborative results were mostly ignored. This usually leads to members with low contribution would usually get the same score as other group members, and inevitably some learners might be "free-riding" or indifferent in learning (Khandaker \& Soh, 2010), making it difficult to give full play to the advantages of collaborative learning.

\subsection{Dimensions of Individual Contribution Evaluation are Scattered and Not Systematic}

Individual contribution is related to but different from the group's overall evaluation.
The evaluation of Individual contribution should not only rely on the evaluation of the overall results and process of the group, but also focus on reflecting the characteristics of students' individual contribution to provide accurate guidance. Some studies only focus on the single link in the collaborative learning process or the knowledge contribution of individual learners in the collaborative learning process, making it impossible to carry out a whole-process and all-round analysis of individual contribution in collaborative learning. Li and Han (2017) believe that in order to improve teachers' teaching process as well as to motivate and regulate learners' learning, the evaluation of blended collaborative learning should conform to such principles: differentiation of evaluation criteria, diversification of evaluation subjects, variety of evaluation methods, comprehensive evaluation content, dynamic evaluation process and beneficial evaluation results. Therefore, multiple learning data sources should be considered to define the dimensions, and attention should be drawn to the characteristics of learners to evaluate the process and results of collaboration.

\subsection{Individual Contribution Evaluation Method Is Single and Difficult to Transfer}

In the blended learning environment, team members generate a large amount of data in the collaboration. With massive and miscellaneous collaboration data and multiple groups of parallel collaboration, it is usually difficult for teachers to monitor the collaboration process, or to evaluate individual contribution objectively and comprehensively (Le, Janssen, \& Wubbels, 2017). Most existing studies use quantitative analysis (Mao, Liu, \& Wu, 2016), social network analysis (Peng, 2012), content analysis and self-evaluation and mutual evaluation combined methods (Ma, Yan, \& Zhang, 2018) to analyze individual 
contribution. The advantage of quantitative analysis and social network analysis method is automatic calculation, but these methods can only display a range of shallow index data (posts, replies, online duration, etc.). Content analysis can capture deeper speech information, but the evaluation subject is single and focuses more on the process. Selfevaluation and mutual evaluation methods can take into account the diversity of evaluation subjects, but some studies show that it is difficult to obtain real evaluation data through questionnaires, and learners may overrate their self-contribution (Yang, Zhang, \& Hu, 2016). It can be seen that it is difficult to obtain scientifically accurate evaluation of individual contribution by using a single method.

Based on the issues identified above, this study aims to build a comprehensive and effective evaluation model of individual contribution in blended collaborative learning. Collaborative discussion data and various analysis methods will be utilized to validate the model. In addition, the characteristics of individual contribution of learners will be explored to support the development of blended collaborative learning.

\section{Evaluation models of individual contribution in blended collaborative learning}

Blended collaborative learning usually takes place in multiple learning environments and individual contribution is evaluated according to both face-to-face collaboration data and computer-supported collaboration data. As content suggests, behavior types and other original data in collaborative learning are mostly stored in forms that are not easy to analyze, and the data concerned in this study may contain data that characterize other collaboration characteristics, it is important to establish new variables to focus on the characteristics of interest (Stefan et al., 2018). Feature engineering method from the field of machine learning is a systematic method to design feature sets based on underlying data. It usually includes four stages: feature construction, feature extraction, feature selection and feature evaluation (Ouyang et al., 2018), it can effectively select features reflecting learning behavior patterns. Considering the complexity of individual contribution evaluation and the richness of data, this study adopts the method of feature engineering to construct individual contribution evaluation model in blended collaborative learning.

\subsection{Individual Contributions in Blended Collaborative Learning}

\subsubsection{Literature review}

From the perspective of activity theory, Mao Gang et al. defined six dimensions for observation indicators, including subject, object, community, tools, rules and division of labor (Mao, Liu, \& Wu, 2016). Santoso et al. evaluated individual contribution in collaborative learning through the use of Wiki, quality of project results, final report and presentation report, etc. (Santoso, Sharfina, $\&$ Sadita, 2018). Khandaker and Soh used ClassroomWiki for detailed data tracking, and analyzed the individual contribution of learners from the dimensions of positive use, negative use, interaction, questionnaire results, and teacher evaluation (Khandaker $\&$ Soh, 2010). Leng Jing et al. used analytic hierarchy process (AHP) to evaluate the individual contribution of group members in online collaborative interaction from the dimensions of "interaction", "debate" and "construction" (Leng, Liuhuang, \& Huang, 2007). Song Chang et al. proposed a relatively comprehensive analytical framework to automatically measure individuals' knowledge 
content contribution and participation behavior in online collaborative discussion from six perspectives of productivity, activation, novelty, activity, reactivity and persistence (Chang, Zheng, \& Hu, 2016). Cacciamani et al. conducted evaluation according to providing information contributions, elaborating information contributions, exploratory contribution, and evaluation contribution (Cacciamani et al., 2012). Sprague et al. believe that the evaluation criteria for individual contribution to collaborative learning should include learners' contribution to the final product of the group (e.g., part of the student report is of high quality) and their contribution to the internal functions of the group (e.g., learners' contribution to the project implementation process) (Sprague, Wilson, \& Mckenzie, 2019).

Looking back on previous literatures, the data indicators on individual contribution vary according to scenarios: some researchers focus on conversations or discussions in collaborative learning, and calculate individual contribution scores by coding group discussions through conversation analysis; Some researchers pay attention to the whole process of collaborative learning, taking the operation on learning platform, discussion between groups and the final group work in the collaborative process as the analysis object. By summarizing previous studies, it can be seen that individual contribution is measured in terms of collaborative knowledge, organization, emotion, etc. Contribution to collaborative knowledge refers to the contribution of knowledge, experience, ideas, creativity and reflection by team members in the collaborative process, which occurs mostly in the process of group discussion online and offline, and promotes the formation of mature solutions or programs; The contribution of collaborative organization refers to the contribution to the coordination process by using collaborative skills, such as time planning, task allocation, and collaborative resource provision, which usually improves the efficiency of group collaboration; The contribution of collaboration emotion refers to the contribution of positive attitude and atmosphere regulation in the process of collaboration, such as relaxed and pleasant discussion atmosphere, optimistic and positive collaboration attitude, motivation and so on.

\subsubsection{Interviews with experts and students}

In order to better understand the process of blended collaborative learning to objectively characterize individual contribution, semistructured interviews were conducted with experts in collaborative learning and students who had participated in blended collaborative learning. The experts indicate that in collaborative learning some groups' internal discussions are dull and difficult to generate sparks of thought, while others' are heated or even become debates. Therefore, the adjustment of group atmosphere and the motivation of group collaboration should be included in the consideration of individual contribution. In addition, experts mention that collaborative organization related problems are prone to occur in collaborative learning, making knowledge construction cannot be promoted through effective communication and mutual inspiration. Most of the interviewed students mentioned workload. Due to the different division of labor of each member, one or two members of the group would undertake the main tasks, while other may loaf of the job, resulting in huge workload differences assigned after discussion. In addition, some students interviewed mentioned that some team members complete their work perfunctorily and the results submitted do 
not meet the requirements. Usually due to the kindness of the students, the group leader or other members tend to re-complete the task to ensure the quality of the group results.

Combining the results of interviews with experts and students, the individual contribution to the team achievements should not be ignored. Such learners exist in real collaboration who actively participate in the preliminary group discussion, but fail to complete the assigned tasks with high quality as required. Therefore, in the evaluation of individual contribution, it is necessary to refer to the group's periodical and final achievements and division of workload to form a new measurement dimension of contribution -- achievement contribution.

\subsection{Dimensions and Methods of the Measurement}

Based on the results of literature review and semi-structured interviews, this study evaluates individual contribution in blended collaborative learning from four dimensions: knowledge contribution, emotional contribution, organizational contribution and achievement contribution, as shown in table 1. Knowledge contribution refers to the knowledge information contribution related to the task theme and able to promote problem solving. Based on the content analysis of discussion text, it is planned to represent it from four dimensions of richness, relevance, novelty and criticism. Emotional contribution refers to the positive emotional attitude shown by learners that can promote positive and harmonious group collaboration. The verified six-dimensional affective classification method is proposed to be used for emotional analysis of discussion text, which divides learning emotions into six types: positive, negative, neutral, insightful, confused and joking (Harris, Zheng, Kumar, \& Kinshuk, 2014). Among them, positive, insightful, confused and joking belong to positive emotional contribution. Organizational contribution refers to learners' contributions such as time management, task allocation, progress monitoring and motivation in order to improve collaboration efficiency, which is analyzed through content analysis of discussion text. Achievement contribution refers to the actual contribution of learners to the outcome of group tasks, which is to be evaluated in combination with the self-report of the task division by the group and the scores of the quality of the results evaluated by the teaching assistants.

Table 1. Dimensions and measurement methods of individual contribution in blended collaborative learning.

\begin{tabular}{|c|c|c|c|c|}
\hline Dimension & $\begin{array}{l}\text { Secondary } \\
\text { Dimension }\end{array}$ & $\begin{array}{l}\text { Data } \\
\text { Source }\end{array}$ & Description & Calculation formula \\
\hline ge & $\begin{array}{l}\text { Richness } \\
\left(\mathrm{KC}_{1}\right)\end{array}$ & Ind & $\begin{array}{l}\text { The proportion of opinions, clues, } \\
\text { schemes and information put forward } \\
\text { by individuals in the total speech }\end{array}$ & $\begin{array}{l}\mathrm{KC}_{1}=\text { Number of individual } \\
\text { speeches / Total Number of speeches }\end{array}$ \\
\hline $\begin{array}{l}\text { Contribution } \\
\quad(\mathrm{KC})\end{array}$ & $\begin{array}{l}\text { Relevance } \\
\qquad\left(\mathrm{KC}_{2}\right)\end{array}$ & $\begin{array}{l}\text { Offline } \\
\text { discussion }\end{array}$ & $\begin{array}{l}\text { The degree to which the individual } \\
\text { is involved in the discussion in topic } \\
\text { understanding, problem solving, } \\
\text { and project advancement }\end{array}$ & $\begin{array}{l}\mathrm{KC}_{2}=\text { Number of personal related } \\
\text { speeches / Number of individual } \\
\text { speeches }\end{array}$ \\
\hline
\end{tabular}




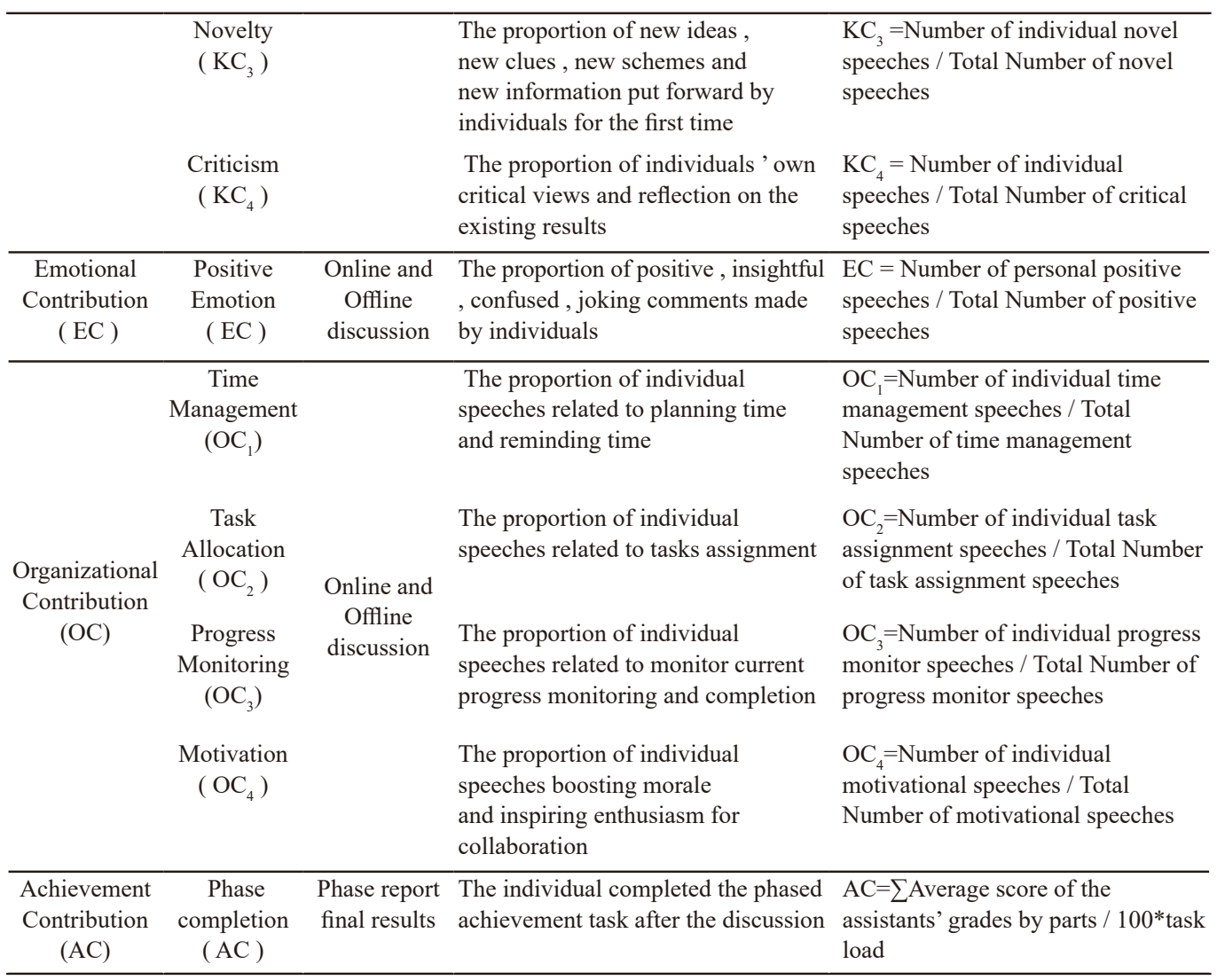

\section{Research Design}

\subsection{Research Context}

In this study, 63 participants in a graduate course of a university in China were selected as participants, who were randomly divided into 14 groups with $4-5$ students in each group. This collaborative learning task lasted for two months, and teams applied the knowledge learned in the course to carry out a problemsolving task of "project selection design and implementation verification". Participants have acquired basic research design ability, research implementation ability and professional knowledge before taking this course. The group's collaboration was conducted in a natural, hands-free manner, with the choice of online or offline discussions, both of which took place under computer-supported conditions. After the teacher releasing the task and requirement of topic selection, the group should complete the periodic and final report according to the requirement of topic selected. In order to reduce the influence of teacher intervention, there were no unified requirements on the number, time, place and form of collaborative discussion for each group. After reporting at each phase, teachers gave feedback and guidance to each group on the content of reporting. The task scenario is shown in figure 1 . 


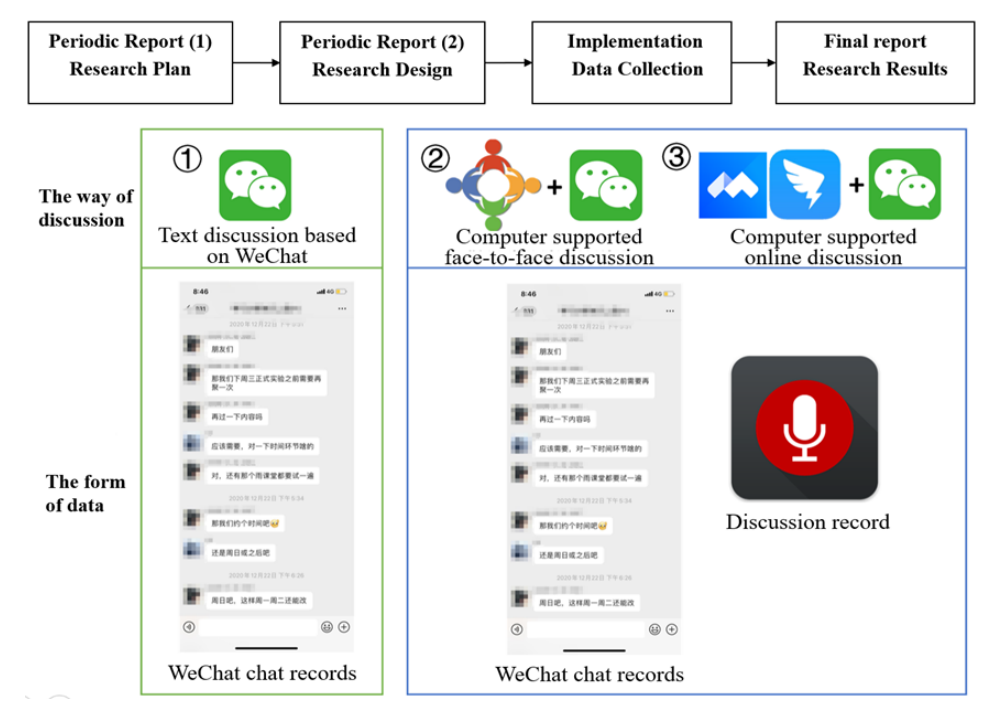

Figure 1. Blended collaborative task scenarios.

\subsection{Data Collection}

The discussion data in the collaboration process were recorded and stored in the form of recordings or chat records. Classify and sort out all kinds of data, clarify important data such as group, speaker, content and time of speech to facilitate data coding. In order to quantify the individual contribution of the group members, this study selected data based on the blended collaborative learning scenarios (text discussion based on WeChat, computer supported face-to-face discussion, computer supported online discussion) horizontally -discussion data covering 63 participants in the same collaborative task phase (phase 1) and vertically -- discussion data in different collaborative task phases in the same group (group B) for analysis.

In order to verify the effectiveness of the individual contribution conceptual model and evaluation results from multiple perspectives, self-evaluation, mutual evaluation and teacher evaluation data were also collected. Group members were asked to complete self-assessment and peer assessment, and provide scores and comments on individual contributions. The teacher evaluation data was from the evaluation conducted by three teaching assistants participating in the course based on the discussion process of each group, and the average score of the three teaching assistants was the final result. The average score of self-evaluation, mutual evaluation and teacher evaluation composed subjective evaluation score of individual contribution.

\section{The Results of the Study}

\subsection{Descriptive Statistics of Individual Contribution Based on Evaluation Model}

\subsubsection{Horizontal data statistics}

According to statistics, 12,857 real-time discussion (face-to-face or online discussion) data and 2,084 WeChat chat records were generated in phase 1 , which were coded by two coders. According to the result of Spearman correlation test, the consistency coefficient of the scores of the two coders was 
$0.872(\mathrm{P}<0.01)$, indicating good reliability. Table 2 shows the related indicator values based on individual contribution evaluation coding table and calculation formula (taking group A as an example).

Table 2. Scoring statistics of individual contribution indicator of collaborative learning in group A.

\begin{tabular}{ccccccccccccc}
\hline $\begin{array}{c}\text { The } \\
\text { way of } \\
\text { discussion }\end{array}$ & $\begin{array}{c}\text { Student } \\
\text { ID }\end{array}$ & $\begin{array}{c}\text { Number } \\
\text { of } \\
\text { speeches }\end{array}$ & \multicolumn{1}{c}{ Richness Relevance Novelty } & Criticism & $\begin{array}{c}\text { Emotional } \\
\text { Contribution }\end{array}$ & $\begin{array}{c}\text { Time } \\
\text { Management }\end{array}$ & $\begin{array}{c}\text { Task } \\
\text { Allocation }\end{array}$ & $\begin{array}{c}\text { Pogess } \\
\text { Monitoring }\end{array}$ & Motivation & $\begin{array}{c}\text { Achievement } \\
\text { Contuibution }\end{array}$ \\
\hline $\begin{array}{c}\text { Real-time } \\
\text { discussion }\end{array}$ & A1 & 128 & 0.2 & 0.953 & 0.124 & 0.16 & 0.2 & 0 & 0.376 & 0.4 & 0 & 0.204 \\
& A2 & 204 & 0.319 & 0.975 & 0.397 & 0.36 & 0.319 & 0 & 0.247 & 0.2 & 0 & 0.212 \\
& A3 & 138 & 0.216 & 0.957 & 0.14 & 0.08 & 0.216 & 0 & 0.153 & 0 & 0.556 & 0.203 \\
& A4 & 164 & 0.256 & 0.994 & 0.331 & 0.4 & 0.256 & 0 & 0.224 & 0.4 & 0.444 & 0.212 \\
& A5 & 6 & 0.009 & 1 & 0.008 & 0 & 0.009 & 0 & 0 & 0 & 0 & 0.173 \\
\hline Wechat & A1 & 69 & 0.361 & 1 & 0.621 & 0 & 0.363 & 0.362 & 0 & 0.5 & 0 & 0.204 \\
text & A2 & 38 & 0.199 & 1 & 0.241 & 0 & 0.2 & 0.155 & 0 & 0 & 0 & 0.212 \\
& A3 & 28 & 0.147 & 1 & 0.034 & 0 & 0.147 & 0.207 & 1 & 0 & 0 & 0.203 \\
& A4 & 38 & 0.199 & 1 & 0.103 & 0 & 0.195 & 0.172 & 0 & 0 & 0 & 0.212 \\
& A5 & 18 & 0.094 & 1 & 0 & 0 & 0.095 & 0.103 & 0 & 0.5 & 0 & 0.173 \\
\hline
\end{tabular}

\subsubsection{Vertical data statistics}

According to statistics, this study selected the discussion data of group B in the phases of making research plans, doing research design, data collection and processing as the object of analysis. Group B produced a total of 3621 pieces of real-time discussion data within the three phases, including 1015 pieces in phase
1,1111 pieces in phase 2, and 1135 pieces in phase 3. According to Spearman correlation test, the consistency coefficient of the scores of the two coders was $0.855(\mathrm{P}<0.01)$, indicating good reliability. Table 3 shows the related indicator values based on individual contribution evaluation coding table and calculation formula.

Table 3. Statistics of scoring results of real-time discussion indicators at each phase in group B.

\begin{tabular}{|c|c|c|c|c|c|c|c|c|c|c|c|c|}
\hline $\begin{array}{l}\text { Collaborat } \\
\text {-ion phase }\end{array}$ & $\begin{array}{l}\text { Student } \\
\text { ID }\end{array}$ & $\begin{array}{c}\text { Number } \\
\text { of } \\
\text { speeches }\end{array}$ & Richness & Relevance & Novelty & Criticism & $\begin{array}{c}\text { Emotional } \\
\text { Contribution }\end{array}$ & $\begin{array}{c}\text { Time } \\
\text { Management }\end{array}$ & $\begin{array}{c}\text { Task } \\
\text { Allocation }\end{array}$ & $\begin{array}{c}\text { Pogess } \\
\text { Monitoring }\end{array}$ & Motivation & $\begin{array}{l}\text { Achievement } \\
\text { Contuibution }\end{array}$ \\
\hline \multirow[t]{5}{*}{ Phase 1} & BI & 257 & 0.256 & 0.93 & 0.24 & 0.129 & 0.234 & 0.5 & 0.313 & 0.478 & 0 & 0.2 \\
\hline & B2 & 179 & 0.178 & 0.994 & 0.218 & 0.2 & 0.177 & 0 & 0.063 & 0.174 & 0 & 0.2 \\
\hline & B3 & 370 & 0.368 & 0.959 & 0.293 & 0.482 & 0.359 & 0.5 & 0.625 & 0.348 & 0 & 0.2 \\
\hline & B4 & 95 & 0.095 & 1 & 0.089 & 0.071 & 0.094 & 0 & 0 & 0 & 0 & 0.2 \\
\hline & B5 & 114 & 0.113 & 1 & 0.16 & 0.118 & 0.112 & 0 & 0 & 0 & 0 & 0.2 \\
\hline \multirow[t]{5}{*}{ Phase 2} & B1' & 363 & 0.327 & 0.978 & 0.318 & 0.271 & 0.326 & 0.5 & 0.413 & 0.583 & 0 & 0.334 \\
\hline & B2' & 151 & 0.136 & 0.94 & 0.095 & 0.167 & 0.136 & 0 & 0.222 & 0 & 0 & 0 \\
\hline & B3' & 412 & 0.371 & 0.983 & 0.458 & 0.438 & 0.37 & 0.5 & 0.333 & 0.417 & 1 & 0.333 \\
\hline & B4' & 81 & 0.073 & 1 & 0.101 & 0.104 & 0.073 & 0 & 0 & 0 & 0 & 0 \\
\hline & B5' & 104 & 0.094 & 0.99 & 0.028 & 0.021 & 0.094 & 0 & 0.032 & 0 & 0 & 0.333 \\
\hline \multirow[t]{5}{*}{ Phase 3} & B1" & 379 & 0.247 & 0.95 & 0.325 & 0.242 & 0.334 & 0.4 & 0.25 & 0.5 & 1 & 0.25 \\
\hline & B2" & 84 & 0.055 & 0.94 & 0.052 & 0.091 & 0.075 & 0 & 0 & 0 & 0 & 0.25 \\
\hline & B3" & 465 & 0.303 & 0.821 & 0.455 & 0.485 & 0.41 & 0.6 & 0.75 & 0.5 & 0 & 0.25 \\
\hline & B4" & 48 & 0.031 & 0.875 & 0.032 & 0 & 0.043 & 0 & 0 & 0 & 0 & 0.25 \\
\hline & B5" & 159 & 0.104 & 0.912 & 0.136 & 0.182 & 0.139 & 0 & 0 & 0 & 0 & 0 \\
\hline
\end{tabular}




\subsection{Validation of Individual Contribution Evaluation Model}

In order to better match the actual context and verify the validity of the calculated results of the indicators, the correlation between the calculated results of the individual contribution indicators based on the real-time collaborative discussion in the first phase and the average score of the subjective evaluation based on the students' self-evaluation, mutual evaluation and teaching evaluation results was verified. The results of indicator calculation show normal distribution, so Pearson correlation test is adopted. The test results are shown in table 4 . There is a significant positive correlation between the average score of subjective evaluation and the scores of richness, novelty, criticism, emotional contribution, time management, task allocation and progress monitoring indicators. There is no significant correlation between the mean score of subjective evaluation and the relevance in knowledge contribution, motivation in organizational contribution and achievement contribution. Combined with the results of correlation test, it can be concluded that the richness, novelty, criticism, emotional contribution, time management, task allocation and progress monitoring are suitable indicators to evaluate the individual contribution of students in the process of blended collaborative learning.

Table 4. Correlation analysis.

\begin{tabular}{|c|c|c|c|c|c|c|c|c|c|c|c|}
\hline & $\begin{array}{c}\text { Number } \\
\text { of } \\
\text { speeches }\end{array}$ & Richness & Relevance & Novelty & Criticism & $\begin{array}{c}\text { Emotional } \\
\text { Contribution }\end{array}$ & $\begin{array}{c}\text { Time } \\
\text { Management }\end{array}$ & $\begin{array}{c}\text { Task } \\
\text { Allocation }\end{array}$ & $\begin{array}{c}\text { Pogess } \\
\text { Monitoring }\end{array}$ & Motivation & $\begin{array}{l}\text { Achievement } \\
\text { Contuibution }\end{array}$ \\
\hline $\begin{array}{c}\text { The } \\
\text { equalization } \\
\text { of evaluation }\end{array}$ & $0.706 * *$ & -0.152 & $0.696 * *$ & $0.611^{* *}$ & $0.701 * *$ & $0.485 * *$ & $0.615^{* *}$ & $0.666^{* *}$ & 0.273 & 0.231 & $0.706 * *$ \\
\hline
\end{tabular}

P.S: ${ }^{* *} \mathrm{p}<0.01,{ }^{*} \mathrm{p}<0.05$

\subsection{Modification of Individual Contribution Evaluation Model}

Based on the above correlation analysis results, it can be concluded that the relevancy in knowledge contribution, motivation in organizational contribution and achievement contribution can hardly reflect individual contribution. The reason may be that the relevancy indicator of knowledge contribution only refers to the extent to which students discuss the initial problem and the content belongs to the scope of learning content, it does not necessarily mean that the ideas presented by the students have made substantial contributions. The proportion of motivation in organizational contribution was fairly low in the group participating in the experiment, indicating that the indicator of motivation was not significant in representing individual contribution. The calculation result of achievement contribution is extremely correlated to the result of division of labor after group discussion. In the process of division of labor, groups mostly used the method of equal distribution or taking turns, and relevant achievements were completed based on the consensus reached in group discussion. Therefore, the significance of achievement is weak in representing individual contribution.

Combining interview results with comments from experts and students in the early stage, and considering the complexity of the process of blended collaborative learning and the comprehensiveness of evaluation, this study holds the mobilization of collaborative motivation and the maintenance of collaborative enthusiasm are valuable in 
the process of collaboration, which is of great significance for the group to remain vitality in the process of collaboration. Achievement contribution focuses on the quality of the output within a given phase, the students who are silent but complete their tasks carefully should be recognized in terms of contribution to the achievement. Therefore, the indicators of motivation in organizational contribution and achievement contribution are still of great significance to the overall consideration of individual contribution of learners. Subsequent analysis aims to eliminate the relevance indicator in knowledge contribution and retain motivation and achievement contribution indicators to form the final individual contribution evaluation model of blended collaborative learning, which is shown in table 5.

Table 5. Evaluation Model of individual contribution of blended collaborative learning (revised).

\begin{tabular}{lc}
\hline $\begin{array}{l}\text { Dimensions } \\
\text { (Criteria layer) }\end{array}$ & $\begin{array}{l}\text { Sec } \\
\text { (In }\end{array}$ \\
\hline Knowledge Contribution & Ric \\
& Nov \\
& Prit \\
\hline Motivation & Pos \\
\hline Organizational Contribution & Tas \\
& Pro \\
Achievement Contribution & The \\
\hline & \\
4.4. Clustering of Individual Contribution \\
Characteristics in Blended Collaborative
\end{tabular}

In this study, K-means clustering method was adopted to explore the characteristics of individual contribution in learners' blended collaborative learning to help teachers or teaching assistants to give targeted guidance to learners' collaboration. In order to clarify the contribution characteristics of learners at different phases, the vertical data of
Secondary dimensions/Indicators

Richness

Novelty

Criticism

Positive Emotion

Time Management

Task Allocation

Progress Monitoring

Motivation

he completion of periodic achievement tasks

five students in group B at three phases of collaboration were included in the cluster data. The silhouette coefficient reaches the maximum value, and the clustering effect is the best when $\mathrm{k}=3$ (as shown in figure 2). Therefore, the number of clusters is set as 3 . After standardizing the original data, K-means clustering is conducted. According to their contribution characteristics, learners can be divided into the following three categories of contributors.

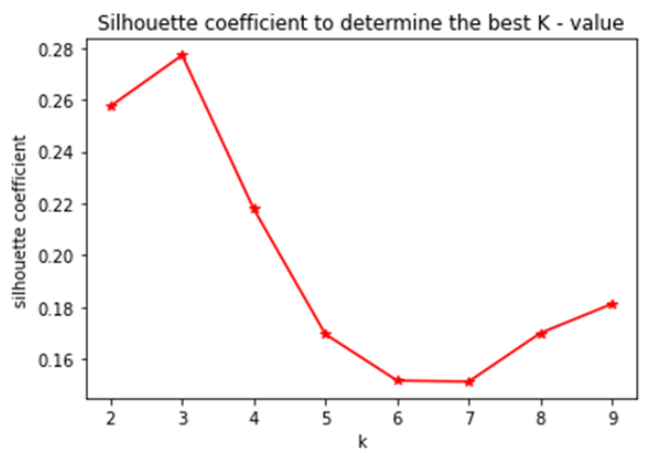

Figure 2. Silhouette coefficient diagram. 


\subsubsection{Cluster 1: Positive contributors}

There are 8 students in this category, including the first and second discussions of learner B1 and the first and third discussions of learner B3, whose characteristics are shown in figure 3. Compared with other categories, these learners' speeches are most and they made contributions in all dimensions. Among them, the organizational contribution of learners is particularly outstanding. Almost all the organizational contributions of the group owe to learners in this category, especially in terms of time management, task allocation and progress monitoring. This kind of learners are generally positive in the collaborative process, and make outstanding contributions to the organization and promotion of the collaborative process, and are active contributors in collaborative learning.

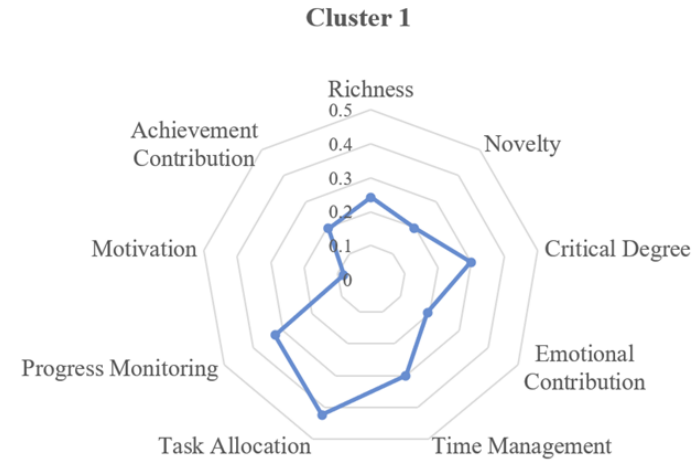

Figure 3. Cluster center radar diagram of cluster 1 .

\subsubsection{Cluster 2: Integrated contributors}

There are 19 students in this category, including the third discussion of learner B1 and the second discussion of learner B3, whose characteristics are shown in figure 4 . Number of speeches of this type of learners is medium, and they show a relatively balanced performance in all dimensions. Such learners contribute to all aspects of group collaboration, and each learner has its own characteristics in different dimensions in the process of collaboration. They can promote group discussion through cooperating with each other and better integrate into collaborative learning. They are integrated contributors in collaborative learning.

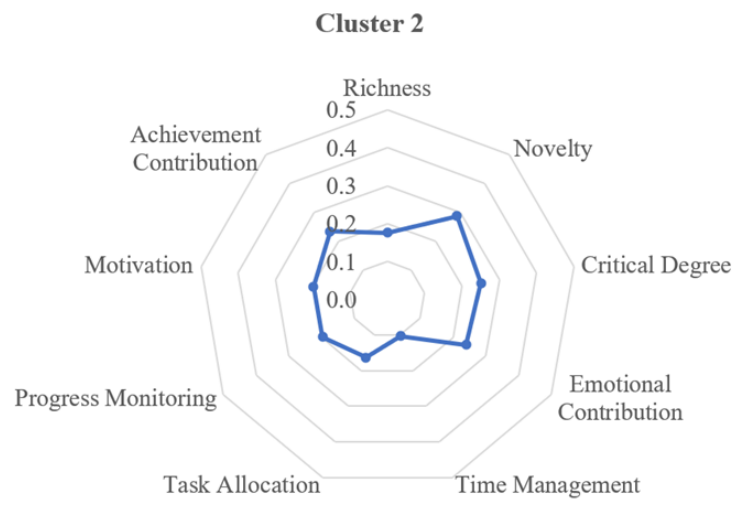

Figure 4. Cluster center radar diagram of cluster 2. 


\subsubsection{Cluster 3: Following contributors}

There are 36 students in this class, including three discussions of learner B2, B4 and $\mathrm{B} 5$, whose characteristics are shown in figure 5. They have shown poor engagement in group discussion, therefore, they get relatively low scores in all dimensions. Regarding organizational contribution, almost no speeches are made, especially in terms of time management and motivation. It can be seen that the overall participation of such members in the collaborative process is not high, and they cannot promote the collaboration process of the group. They only make intellectual and emotional contributions to group collaboration under the impetus of several other types of contributors, so they are following contributors in collaborative learning.

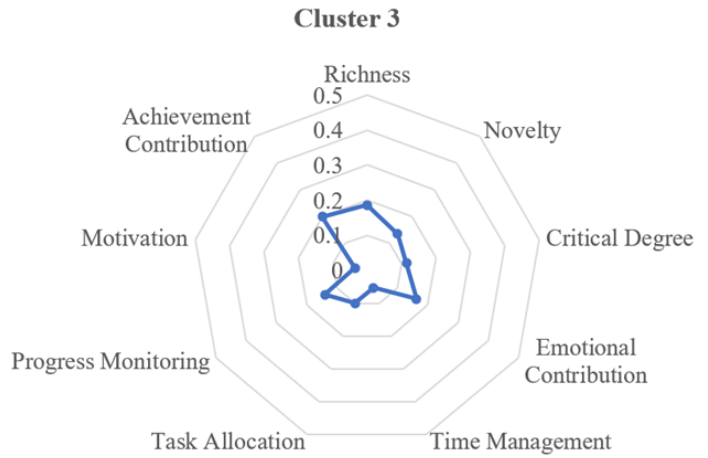

Figure 5. Cluster center radar diagram of cluster 3.

\section{The discussion of the research}

\subsection{Analysis and Discussion}

\subsubsection{Relevance in real-time discussion is a big challenge}

By comparing the relevance of realtime discussion and WeChat discussion, it can be found that the relevance of WeChat discussion is 1 , and the speeches of group members were all pertinent to the topic selection and collaboration of the group. In contrast, in real-time discussion, there were more or less unrelated content in terms of relevancy of knowledge contribution. Notably, the relevance was higher for those who spoke less in groups than for those who spoke more. In collaborative learning, most of the content discussed by learners in WeChat is the auxiliary information to promote the process of collaboration, such as the appointment of discussion time and sharing of relevant information. While the actual views in collaborative learning are mostly generated in real-time discussion, thus real-time discussion is the main approach of collaborative learning. Real-time discussion is the main way of group collaboration, and in this study, this type of discussion lasted for a long time, so it is difficult to avoid discussing irrelevant content during the collaboration, especially for students who speak a lot, high relevance becomes more challengeable.

\subsubsection{Characteristics of learners' individual contribution are consistent in the collaboration process}

The results of cluster analysis showed that 
in group B, two discussions of learners B1 and B3 were clustered as positive contributors, and three discussions of learners B2, B4 and B5 were all clustered as following contributors, that is, different discussions of the same learners were basically clustered into one group. It can be seen that the characteristics of individual group contribution of learners were highly consistent in the early, middle and late phases, and the collaborative contribution style tended to be stable. Plasticity is the premise of intervention on learners' collaborative contribution (Yin \& $\mathrm{Wu}, 2019$ ). Therefore, in the early stage of group collaboration, combining with the analysis results of individual contribution characteristics, teachers' timely introduction of certain external teaching scaffolding can exert a positive impact on group collaboration behavior (Cai \& Gu, 2015).

\subsubsection{Individual contribution characteristics of learners in the same group influence each other}

According to the cluster analysis results, among learners, the number of positive contributors is the least, and most of them play a leading role in the group. In contrast, the number of following contributors is the largest, indicating the phenomenon of "freeriding" is common. By analyzing the types of contributors in each group, it is found that there are differences in the composition of contributors in different groups. For example, group A was composed of three integrated contributors and two following contributors. In the process of collaboration, the contributions of group members were relatively average and had a high degree of collaboration activation. Group B was composed by two positive contributors and three following contributors. In the process of group discussion, students B1 and B3 led the group discussion and scored much higher in organizational contribution than other group members. The other group members hardly made any comments on organizational contribution and were passive in controlling the direction and progress of group discussion. This indicates that when there are strong contributors in the group, other group members are more likely to become followers of contributors and passively participate in group collaboration; When the contribution difference among group members is small, the members who passively participate in group collaboration are relatively few, and the members may give full play to their own characteristics and advantages to form a harmonious collaborative atmosphere. Therefore, in the same group, there are mutual influence between characteristics of individual contribution of learners.

\subsection{Supporting Strategies for Blended Collaborative Learning}

\subsubsection{Determine the grouping method according to the individual contribution characteristics of learners}

This study found that, within the same group member's individual contribution characteristics influence each other. Therefore, teachers should give full consideration to the main individual contribution characteristics of learners showed in the previous collaborative learning, and make heterogeneous grouping as far as possible, so as to promote learners to give full play to their own advantages and actively participate in collaborative learning. For example, positive contributors mostly play a leading role in the group. If there are too many such learners in one group, other types of learners will be in a passive state and their input will be reduced. Therefore, positive contributors can be scattered in different groups, and the proportion of positive contributors in each group should not exceed $20 \%$. Integrated contributors can participate in 
the collaboration process well and have their own unique advantages. Therefore, integrated learners with outstanding contributions in different dimensions should be assigned to one group during grouping, so as to avoid the imbalance in the performance of the group in different dimensions caused by learners with the same advantages in the same group. The following contributors are generally the majority of learners and should be equally distributed in each group. It can also be considered to designate the following contributors as group leaders to promote their active participation in the collaboration process.

\subsubsection{Design and develop a blended collaborative learning individual contribution dashboard}

The process of blended collaborative learning is complicated, and teachers cannot understand the individual contribution of each learner through direct observation, so it is difficult to provide accurate and realtime guidance for learners. It is also difficult for learners to realize their contribution to group collaboration in time and to adjust their subsequent collaborative learning. Therefore, it is important to design dashboards for teachers and learners that can visualize individual contributions in blended collaborative learning. Among them, the teacher-side dashboard can include the presentation of each indicator of individual contribution, word frequency analysis of discussion content, collaboration weaknesses and suggestions, etc., to help teachers understand the progress of each group discussion and provide corresponding guidance. The student-side dashboard can include the statistics of learners' speeches, individual contribution scores for each member in the group, the analysis of the advantages of learners' individual contribution, the analysis of learners' word frequency in discussion, the types of learners' individual contribution and suggestions for collaboration, etc.

\subsubsection{Providing individualized intervention according to the contribution characteristics of learners}

A high-quality assessment framework can not only provide fair scores and give learners the evaluation they deserve, but also encourage learners to try their best to complete collaborative tasks. Meanwhile, it provides important data support and strategy suggestions for teachers to carry out relevant courses. According to the contribution characteristics of learners in collaborative learning, teachers can provide corresponding intervention measures for them: for example, for positive contributors and integrated contributors, they can be provided with collaborative learning role scripts to guide them to lead other members in the group to participate in collaboration. For following contributors who are less collaborative, teachers may set clear criteria before the collaboration, and then evaluate each student's performance through communication and observation in each phase of the task, to give more responsibility learners was slightly higher than the average scores of the group (Xu $\&$ He, 2016). This will make learners realize personal contributions will get a reasonable return and improve their motivation, perception and ability to participate in group projects (Johnston \& Miles, 2004).

\section{Summary and prospect}

Based on the summary of the existing individual contribution evaluation studies, this study adopted the feature engineering method, combining the results of literature review, expert teachers and students' interviews, to build the evaluation model of individual contribution in the blended collaborative learning. The recordings and text data of the 
discussion of blended collaborative learning were collected in a non-intrusive way, and the individual contribution evaluation model was verified and modified based on the data. Through the clustering analysis of the characteristics of the learner's contribution, the learners' contribution type was summed up. The research result can support teachers and learners' timely adjustment of collaborative learning status on the basis of individual contribution analysis results, promoting accurate and learner-centered teaching, and helping teachers evaluate individual contribution in collaborative learning more accurately, and improve collaborative efficiency.

In future studies, in addition to learners' speech data during discussion and chat records in WeChat group, multi-modal data such as learners' sitting position, electroencephalography (EEG), heart rate and galvanie skin response (GSR) may also be used as important data sources to explore the characteristics of learners' individual contribution. In addition, corresponding interventions and visual dashboards can also be designed based on the individual contribution evaluation model and used in different grades or collaborative tasks to improve actual effectiveness of the model.

\section{Corresponding author}

\section{Fati $W u$}

wft@bnu.edu.cn

School of Educational Technology

Beijing Normal University

\section{References}

Bacon, D. R., Stewart, K. A., \& Silver, W. Skjk. (2014). Lessons from the Best and Worst Student Team Experiences: How A Teacher Can Make the Difference. Journal of Management Education (5), 467-488.

Cai, H. Y., \& Gu, X. Q. (2015). Design Research on Cognitive Development in Computer-supported Collaborative Learning Environment. Open Education Research (04),81-88.

Cacciamani, S., Cesareni, D., Martini, F., Ferrini, T., \& Fujita, N. (2012). Influence of Participation, Facilitator Styles, and Metacognitive Reflection on Knowledge Building in Online University Courses. Computers \& Education (3), 874-884.

Chang, X., Zheng, Y., Hu, H., \& Li, Y. (2016). Measuring and Visualizing Individual Contributions in Online Collaborative Discussions. IEEE International Conference on Advanced Learning Technologies. IEEE.

Gao, X. (2021). From Cooperative Learning to Learning Cooperation: Practical Improvement of Current Classroom Cooperation. Theory and Practice of Education (04),61-64.

Harris, S. C., Zheng, L., Kumar, V., \& Kinshuk. (2014). Multi-Dimensional Sentiment Classification in Online Learning Environment. T4E 2014. IEEE.

Khandaker, N., \& Soh, L. K. (2010). Assessing Individual Contributions to Groupwork by A Summary of Tracked Computersupported Collaborative Activities. Frontiers in Education Conference. IEEE.

Li, F. Q., \& Han, X.L. (2017). The Construction and Demonstration of Blending Teaching Quality Evaluation System. China Educational Technology (11), 108-113.

Le, H., Janssen, J., \& Wubbels, T. (2018). Collaborative Learning Practices: Teacher and Student Perceived Obstacles 
to Effective Student Collaboration. Cambridge Journal of Education (48), $1-20$.

Leng, J., Liuhuang, L.Z., Huang, R. H., \& Li, Q. (2007). Synthetic Performance Assessment of Group Member in Online Collaborative Learning. Modern Educational Technology (03),51-56.

Lucy, J., \& Miles, L. (2004). Assessing contributions to group assignments. Assessment \& Evaluation in Higher Education (6), 751-768.

Mao, G., Liu, Q. T., \& Wu, L. J. (2016). The Analysis Model of Group Collaborative Learning Based on the Activity Theory and Its Application. Modern Distance Education Research (03),93-103.

Ma, Z. Q., Yan, X.J., \& Zhang, H. Y. (2018). The Design and Applied of Assessing Individual Contribution in Webbased Collaborative Learning. Modern Educational Technology (10),87-93.

Ouyang, J. Y., Fan, Y. Z., Luo, S. F., Ji, J.M., \& Wang, Q. (2018). Feature Engineering: The Method of Detecting Learner Behavior Patterns in Learning Analytics Field. Modern Educational Technology (04),13-19.

Peng, S. D. (2012). Indicator Definition and Method Application of the Community Network Characteristics Analysis in Blended Collaborative Learning. Open Education Research (02),92-98.

Santoso, H. B., Sharfina, Z., \& Sadita, L. (2018). Evaluating Student Project in a Human-computer Interaction Course: Collaborative Learning Behavior and Performance Perspectives. 2017 7th World Engineering Education Forum (WEEF). IEEE.

Sprague, M., Wilson, K. F., \& Mckenzie, K. S. (2019). Evaluating the Quality of Peer and Self Evaluations as Measures of Student Contributions to Group Projects. Higher Education Research \& Development (1),
1-14.

Stefan, S., Srecko, J., Vitomir, K., Ryan, B., Dragan, G., Cui, X., \& Wang, J. (2018). Tools for Educational Data Mining. Journal of Open Learning (01),37-47.

Xu, L. L., \& He, J. W. (2016). Social Loafing Research of Group Projects in Colleges. Special Zone Economy (11),174-176.

Yang, C., Zhang, G., \& Hu, Y. N. (2016). Review on Evaluation Mechanism of Group Cooperative Learning. China Educational Technology \& Equipment (24), 6-8+17.

Yin, B. Y., \& Wu, F. T. (2019).Principles and Model Design of Online Intervention of Learning Habits. E-Education Research (12),72-79. 